\title{
Marketing Strategies in Knowledge-Based Companies of ICT Services
}

\author{
Vahid Mohammadi ${ }^{1} \&$ Ismail Jafarpanah ${ }^{1}$ \\ ${ }^{1}$ Faculty of Management Department, Tehran University, Tehran, Iran \\ Correspondence: Vahid Mohammadi, Faculty of Management Department, Tehran University, Tehran, Iran. \\ E-mail: drasgari.n@gmail.com
}

\author{
Received: May 3, $2014 \quad$ Accepted: June 9, 2014 Online Published: August 29, 2014 \\ doi:10.5539/jms.v4n3p199 URL: http://dx.doi.org/10.5539/jms.v4n3p199
}

\begin{abstract}
The aim of this study is to evaluate the company's business strategy in knowledge-based companies of information and communication technology (ICT) services. The purpose of this research is applicable and is of descriptive research categories. The statistical populationincludes 80 executives of knowledge-based companies based in science and technology parks of Tehran University,campus, Isfahan,Khorasan and Farsthat were engaged in the field of ICT services.By using Cochran's formula, 60 executives were estimated as the sample, and the samples were selected randomly.Main research tool was a questionnaire that its validity was confirmed by a panel of experts in different aspects of validity, content and structure. The reliability of the survey tool was confirmed by Cronbach's alpha coefficient, which represents the suitable reliability of research tool $(92 \%)$. The results showed that the lack of adequate financial resources incompanies has been an important weakness. The main strength of the companies is to choose unique product or special one with clear market demand. The main threat in these companies is the rapid advance of technology and the lack of investment in new technologies. The main opportunity for these companies is to cooperation with industry in the development of products and services. The existing strengths in knowledge-based companies are more than their weaknesses. On the other hand, threats are stronger than opportunities, so the strategic deployment flexibility is in ST area and dominant strategy is defined as diversification strategy.
\end{abstract}

Keywords: marketing strategy, SWOT analysis, diversification strategy, theknowledge-based companies

\section{Introduction}

Knowledge-based enterprises play an important role in the efficiency of production, crystallization of knowledge on new products and services, promotingeconomic level and prosperity and wealth creation and value added in a society andthe movement towards innovation and change in the composition of a company's products and services is founded within the scope of the knowledge-based company's activities (Allahyarifard \& Abbasi, 2011). In fact, knowledge-based enterprises based on publication, dissemination and use of information, build knowledge and its creation. These enterprises adopt themselves with emerging changes more than other companies in business environment and tryto survive in competitive environment (Behboudi \& Amiri, 2010). According to Albert (2010), the more the knowledge-based enterprise uses knowledge in its own structures, it will add to its value and will create more evolved cycle from development.

Despite numerous researches have been done with an aim to provide a model for commercializing innovation, however, most of their results have been criticized. Moreau (2006) has concluded that the proposed model for commercializing innovations in knowledge-based companies basically arenot practical and each company should find appropriate strategy for commercialization and marketing depending on the type of product, level of fitness or community needs, size of company and level of applied technology. Due to this fact and the need to provide solutions for commercialization of innovations in the field of ICT services, this study presents a framework for commercialization of these innovations as a research problem.

The successful commercialization of innovation and new achievements requires at least sufficient demand, potential advantage of technology to meet those demands and an organization or entrepreneur with the managerial abilities and suitable marketing to deliver the final product to the market (Pour Ezzat et al., 2010). Creating value for customers and itsmanagement is one of the company's key success factors and knowledge-based companies (Berg, 2005). These companies also play an important role in explanation and modeling of the production,research and developmentprocesses, scientific and technological enrichment, training, 
education and human development, knowledge transfer and publication and dissemination of innovation in each country (Farjadi and Riahi, 2007). The successful respond of these companies in a very dynamic environment depends on these companies in providing innovative and technological products to the market, acquiring customers and finding ways to provide products and services. Therefore, experts have discussed knowledge of marketing in these enterprises as the basis for sustainable competitive advantage (Markman et al., 2008).

The common characteristics of these enterprises include the relatively high potential of growth, the need to external financing due to the time consuming of product development, focusing on specific markets for which there is a high demand worldwide, tendency to clustering in specific areas that have been split from universities/ large companies, the tendency set in an incubator / science parks, the tendency to transfer technology within a region, establishing by teams and setting up by entrepreneurs with higher education (Allahyarifard \& Abbasi, 2011).

Delivering the product to themarket,is the most expensive, riskiest and the weakest stage of new product development process. By accelerating the competition, nowadays most successful companies put their resources and competitive ability at commercial level. What is certain is that the way of feeding and continuation of knowledge-based companies passes the marketing principle and in this complex and uncertain environment, to have a marketing strategy will be essential (Radfar and et al., 2009).

The Knowledge-based companies can have two main strategies to enter the market. First, they can enter the market as a pioneer and innovator or as a follower. The main principle to choosepioneer strategies is to have an invention or certain innovation in the market. In this strategy the first step is market research strategies that comes with an invention to meet needs or innovation in the product after exploration of market demand and its optimal processing. This invention will fail soon if it is not derived from the market demand (Malekzade, 2007). Being a pioneer requires to explore the market demand and speed in product designing that if any of these two principles are not taken into account, the cost of developing and entering the market will be wasted. The features of being the pioneer in the market involves high risk acceptance, requiring substantial financial resources,faster and easier to access than others to primary sources and suppliers, will be considered as product measurement index of future manufacturers if it is successful and it defines the rules of production and distribution and quality and price (Bagheri, 2013). The follower strategy means that it is not your invention's product but because of high market demands and small supply of manufacturers, the existence of follower company will be justified. In some cases, the follower company also can play a successful and effective role in the market with improving product (in terms of technology, quality or price). The features of this strategy can be adopted in benefitingfromand modifying others errors in designing the product and market position, reducing costs in identifying primary sources and suppliers, reducing costs in identifying target markets, the possibility of taking advantage of the most recent technology and the need to adhere the standards set by the pioneer (Fakour \& Ansari, 2011).

Mac Gann (2007) in his studies on the history of successful implementation of the marketing strategy in knowledge-based companies suggests that the implementation influences the strategic efficiency but he did not test the existence of a relationship between the quality of marketing strategy implementation and efficiency. Zhang (2003) argues that high incomecompanies have stronger capacity than mean of marketing strategy implementation. Albino et al. (2004) argue that a company can have its capacity to preserve its competitiveness until it accomplishes the unique pricing strategy and in that strategy, none of those unknown competitors do not pay attention to this issue simultaneously and other companies also are not able to replicate profitable strategy. Mudambi and colleagues (2009) noted that marketing strategy can be underlying various structural strategies that involve positioning, pricing, distribution and global strategies. The successful strategy of marketing requires sustainable competitive advantage and planning and its accomplishment.

The marketing process of knowledge-based companies' products is not a linear and irregular process and actually there are several activity groups that each group is a set of nonlinear and irregular activities.Five steps of technology knowledge (identifying users of new technologies and providing basic information to them), convincing (paying attention and creating heartbeliefs in customers about the usefulness of new technologies), making decisions (consumer decision making regarding acceptance or rejection of technology), and applying technology and confirming results are of important stages in marketing the products of knowledge-based companies (Bandarian, 2009).

Thesales and technology marketing as a product and technologicalproducts, have sensitivity and special features that should be considered. Considering these issues SEMs (small, medium enterprises) has a decisive role. Commercialization of research results is the most important and the most essential responsibility of knowledge-based companies (SarmadSaeidi \& Mamaghani, 2011). In fact, the existencephilosophy of these 
companies is offering and selling new ideas and their commercialization. The entering gateway known as the primary commercialization or the stage of offering ideas is indeed a critical point, because at this stage the cost of failure is very expensive. The ability of these companies in successful sales of new products or services is influenced by two factors of orienting in the market and having perspective insight and understanding customer needs beyond what they mention themselves (Hosseini \& Araste, 2013).

Knowledge-based companies should consider five main factors in choosing marketing strategies:

-Relative advantage: indicates the degree of new technology advantage to previous or present methods and products;

-Compatibility: indicates the degree of new technology compatibility with acceptablevalues ,previous experiences and customer needs;

-Complexity: indicates the degree of complexity and new technology difficulties in terms of understanding and using them;

-Possibility of trail use: indicates the degree of competition in implementing new technology on small scale (i.e. It could be achieved an evaluation of the future results);

-Observe ability: indicated the degree of simplicity and intelligibility of the results produced and using new technology for users and other decision makers (Moghimi et al., 2011).

Mousaii (2008) believes that a comprehensivedevelopmentliterature and commercialization of products in industries have applications directly in successful commercializing of technology from research centers to the market.Finally, nine key factors that affect the marketing process and the commercialization of new products are unique, superior, distinctive and valuable product, special focus on the part of the market, the existence of a clear and certain definition of the end product, using of multi-functional teams with task-oriented leaders, using leverage feature of existing competence, market size and its growth attractiveness and technological competence and the quality of its implementation.

Mohammadi (2009) believes that the key factors of success in commercialization of technology is to adapt technology advantages with market demands, the lack of competing technologies, the existence of facilitating and accelerating principles, direct effect on human health, ease of use or process and cost and profit. Enterprises use different methods and patterns for commercialization process, according to the stage of commercialization, we can define three main strategies:

-Reactive commercialization: After doing a research project and achieving its results, commercialization takes place. It is usually used for technologies that are achieved as a corollary during implementing great research projects;

- Proactive commercialization (conventional research): before beginning a research project, commercialization takes place and after making sure of commercialization (contracts with business partners) the research project begins.This method is suitable for the products that are determined before developing the nature of technology and quality of its performance or it is the certain definition of product or high possibility for achieving the desired results;

- Concurrent Commercialization: Before beginning a research project, commercialization begins and along with conducting research project coincidently the commercialization considerations are done stage by stage parallel (Mousaii et al., 2008).

\section{Methods and Materials}

The current research is quantitative in terms of paradigm and it has used survey strategy according to the extensive range of research. In this study, in terms of direction and purpose is a type of the applied research. In terms of time, due to the fact that it is determined at a particular time, it is a ofsingle cross-sectional studies. The statistical population includes 80 executives of knowledge-based companies based in science and technology parks of Tehran University, campus, Isfahan, Khorasan and Fars that were engaged in the field of ICT services. By using Cochran's formula, 60 executives were estimated as the sample, and the samples were selected randomly. Main research tool was a questionnaire that its validity was confirmed by a panel of experts in different aspects of validity, content and structure. The reliability of the survey tool was confirmed by Cronbach's alpha coefficient, which represents the suitable reliability of research tool (92\%). To identify appropriate strategy in marketing the products of knowledge-based companies, SWOT analysis was used. In order to identify weaknesses, strengths, threats and opportunities, they were identified first by literature review.Then, their list was provided to 20 experts in the field of marketing and commercialization of these companies ' products and 
they were asked to rate their importance. After gathering information, in each part, 10 components with the highest priority were selected and were provided to the managers of these companies.

\section{Findings}

- Demographic characteristics of respondents: the average age of the studied managers is 46.65 years. 75 percent of managers are men, and 68.7 percent of managers have master degrees. Studies show that on the average respondentshave 14.59 years of work experience. 34 percent of respondents studied fields related to industry and 30 percent studied fields related to Information Technology.

- Weaknesses in marketing the products of knowledge-based companies: a review of the results of the analysis of the weaknesses of thesecompanies in marketing their products showed the lack of adequate financial resources in companies is the most important weakness of the enterprise andin the next insufficient priorities of companies' manpower in marketing the products,there are poor fit of some products with the capabilities and ability of company and the lack of access to after sales services of some products. Prioritization of weaknesseshas been made based onthe coefficient of variation. The coefficient of variation is obtained from the ratio between the standard deviation and the mean of each item and is a more appropriate index for prioritization. The higher the mean of response is, indicates that respondents evaluate the item more important and the less the standard deviation is, indicates that the greater convergence is between the views of respondents.According torespondents, the lack of appropriate product design and insufficient return on investment (less profitability than asset) has the lowest priority in weaknesses. The results have been provided in Table 1.

Table 1. Prioritization of marketing weaknesses in knowledge-based companies

\begin{tabular}{|c|c|c|c|c|}
\hline Weaknesses & Mean & Standard deviation & $\begin{array}{l}\text { Coefficient of } \\
\text { variation }\end{array}$ & rate \\
\hline $\begin{array}{l}\text { Lack of adequate financial resources for the } \\
\text { companies }\end{array}$ & 6.2 & 2.68 & 0.430 & 1 \\
\hline $\begin{array}{l}\text { Insufficient manpower capabilities of } \\
\text { companies in the areas of Product Marketing }\end{array}$ & 5.7 & 2.59 & 0.454 & 2 \\
\hline $\begin{array}{l}\text { Poor fit of some products with competence } \\
\text { and operations of company }\end{array}$ & 5.8 & 2.71 & 0.467 & 3 \\
\hline Lack of access to the after-sales service & 5.7 & 2.69 & 0.467 & 4 \\
\hline $\begin{array}{l}\text { Mismatch of knowledge-based products with } \\
\text { customer needs }\end{array}$ & 5.7 & 2.79 & 0.493 & 5 \\
\hline $\begin{array}{l}\text { Natural barriers of products such as } \\
\text { complexity and multidisciplinary nature }\end{array}$ & 6.2 & 3.06 & 0.495 & 6 \\
\hline $\begin{array}{l}\text { Lack of understanding of the market and the } \\
\text { uncertainty of the target market for some } \\
\text { products }\end{array}$ & 6.3 & 3.13 & 0.497 & 7 \\
\hline Failure to accurately forecast marketdemand & 5.2 & 2.73 & 0.526 & 8 \\
\hline $\begin{array}{l}\text { Insufficient return on investment (less } \\
\text { profitability than asset) }\end{array}$ & 5.2 & 2.81 & 0.537 & 9 \\
\hline Lack of appropriate product design & 4 & 2.74 & 0.682 & 10 \\
\hline Mean & 5.6 & 2.79 & 0.500 & \\
\hline
\end{tabular}

- Strengths in marketing the products of knowledge-based companies: a review of these companies' marketing strengths showed that the most important strength of these companies is selecting unique and special product with a clear market demand and in nextpriorities, thereare lack of competing technology and nobility of product, targeted focusing on the market segment paying attention to product attractiveness in the market( appropriate design).According to respondents ,developing products with high added value and high academic skills in production have low priority. The results are provided in Table 2 . 
Table 2. Prioritization of marketing strengths in knowledge-based companies

\begin{tabular}{|c|c|c|c|c|}
\hline Strengths & Mean & Standard deviation & $\begin{array}{l}\text { Coefficient of } \\
\text { variation }\end{array}$ & rate \\
\hline $\begin{array}{l}\text { Selecting a unique or special } \\
\text { productwith clear market demand }\end{array}$ & 7.6 & 2 & 0.263 & 1 \\
\hline $\begin{array}{l}\text { Lack of competing technology and } \\
\text { nobility of product }\end{array}$ & 7.9 & 2.12 & 0.270 & 2 \\
\hline Targeted focusing on market segment & 8.1 & 2.36 & 0.291 & 3 \\
\hline $\begin{array}{l}\text { Paying attention to market } \\
\text { attractiveness in the market (appropriate } \\
\text { design) }\end{array}$ & 7.9 & 2.33 & 0.294 & 4.5 \\
\hline $\begin{array}{l}\text { Reducing costs of product } \\
\text { commercialization }\end{array}$ & 7.7 & 2.27 & 0.294 & 4.5 \\
\hline Training commercialization methods & 7.4 & 2.35 & 0.318 & 6 \\
\hline $\begin{array}{l}\text { Use of various commercialization } \\
\text { methods }\end{array}$ & 6.5 & 2.12 & 0.324 & 7 \\
\hline $\begin{array}{l}\text { Having high academic skills in } \\
\text { production }\end{array}$ & 6.9 & 2.32 & 0.337 & 8 \\
\hline Use of specialists & 7 & 2.49 & 0.355 & 9 \\
\hline $\begin{array}{l}\text { Developing products with high added } \\
\text { value }\end{array}$ & 6.9 & 2.47 & 0.356 & 10 \\
\hline Mean & 7.39 & 2.28 & 0.310 & \\
\hline
\end{tabular}

- Threats in the Product Marketing of knowledge-based companies: The review of threats of product marketing in these companies (table3) indicates that the most important threats in these companies are rapid advancement of technology and lack of investments in new technologies and in the next priorities of customer uncertainty about knowledge-based products, is a change in customer preferences due to rapid changes in technology and lack of commercializationbetween managers at governmental level.The least threat in knowledge-based product marketing is in the absence of appropriate promotionalcapacity in the country and the lack of a ready production line.

Table 3. Prioritization of marketing threats in knowledge-based companies

\begin{tabular}{|c|c|c|c|c|}
\hline Threats & Mean & Standard deviation & $\begin{array}{l}\text { Coefficient of } \\
\text { variation }\end{array}$ & rate \\
\hline $\begin{array}{l}\text { The rapid advancement of technology } \\
\text { and lack of investment in new } \\
\text { technologies }\end{array}$ & 7.6 & 2.02 & 0.266 & 1 \\
\hline $\begin{array}{l}\text { Customer uncertainty about knowledge- } \\
\text { based products }\end{array}$ & 7.4 & 2.46 & 0.335 & 2 \\
\hline $\begin{array}{l}\text { Changes in customer preferences due to } \\
\text { rapid changes in technology }\end{array}$ & 6.8 & 2.41 & 0.354 & 3 \\
\hline $\begin{array}{l}\text { Lack of commercialization experience } \\
\text { between managers at governmental level }\end{array}$ & 6.5 & 2.31 & 0.356 & 4 \\
\hline $\begin{array}{l}\text { Lack of enough motivation for } \\
\text { researchers }\end{array}$ & 7.01 & 2.52 & 0.359 & 5 \\
\hline $\begin{array}{l}\text { Performing formalities of } \\
\text { commercialization contracts }\end{array}$ & 7.1 & 2.75 & 0.388 & 6 \\
\hline To getinternal and external certificates & 6.7 & 2.63 & 0.395 & 7 \\
\hline $\begin{array}{l}\text { Difficulty in getting the product } \\
\text { standard }\end{array}$ & 6.9 & 2.78 & 0.396 & 8 \\
\hline The lack of ready production line & 7.2 & 2.86 & 0.399 & 9 \\
\hline $\begin{array}{l}\text { Lack of appropriate promotional } \\
\text { capacity in this country }\end{array}$ & 6.2 & 2.49 & 0.602 & 10 \\
\hline Mean & 6.93 & 2.51 & 0.365 & \\
\hline
\end{tabular}

Opportunities in knowledge-based product marketing: The review of existing opportunities in external environment for these companies, the results indicated that the most important opportunity for these companies is cooperation with industry in developing products and services and in the next priorities there are exemption 
from taxation, access to credit and access to legal services. The least opportunity from respondent point of view are modeling of companies or successful global organizations and awareness if product sales perspective in global market.

Table 4. Prioritization of marketing opportunities in knowledge-based companies

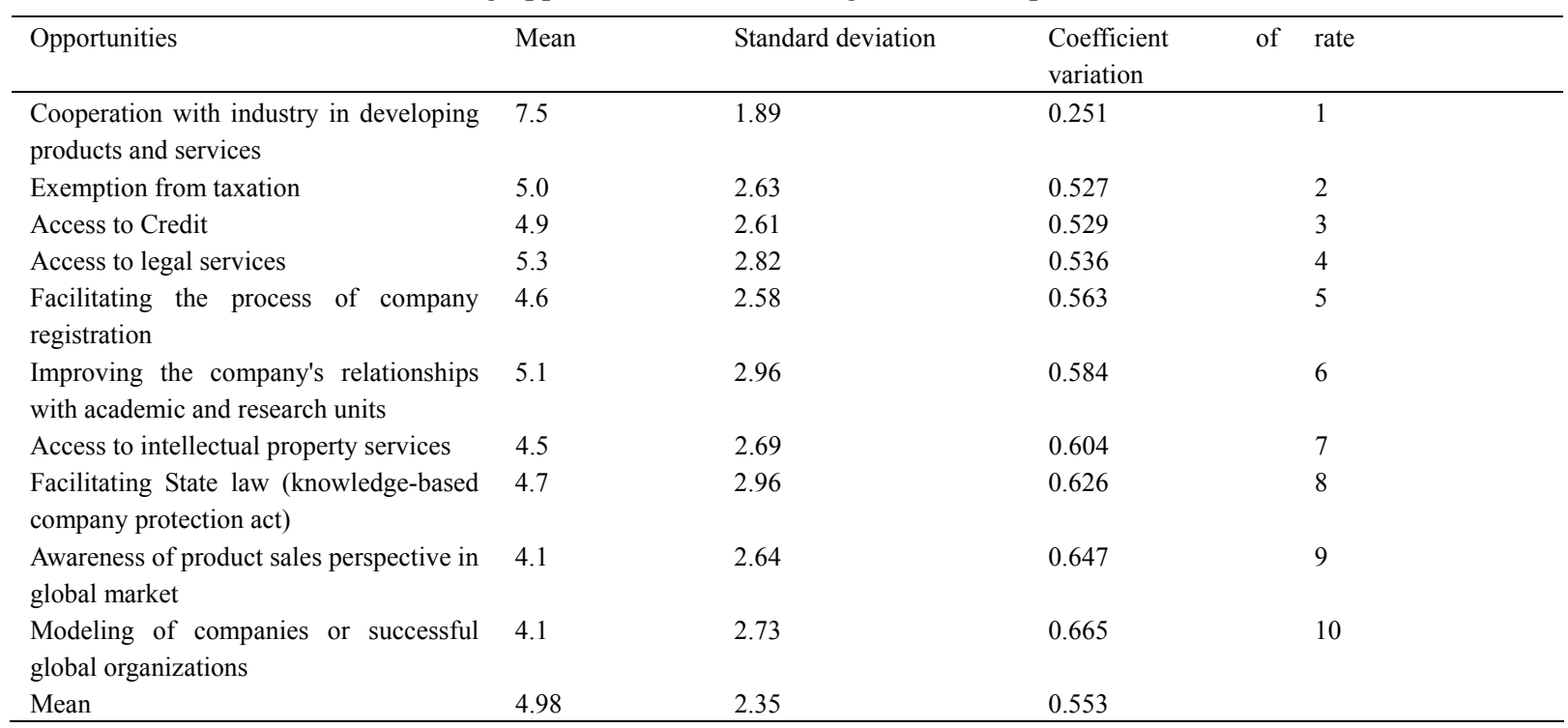

The review of weaknesses, strengths, opportunities and threats are provided in table 5 . As it is clear the strengths of knowledge-based companies are more than their weaknesses but threats are more than opportunities. According to the four components, following strategies can be taken into account in knowledge-based product marketing:

- Strategy of Strengths and Opportunities (SO): The strategy of using the organization's strengths and exploiting the existing opportunities (offensive strategy);

- Strategy of Strengths and threats (ST): The strategy of using of the strengths of the organization in order to deal with threats (diversification strategy);

- Strategy of weaknesses and opportunities (WO): the strategy of taking advantage of potential benefits that are hidden in environmental opportunities in order tocompensate weaknesses (shiftstrategy);

- Strategy of weaknesses and threats (WT): famous strategy to minimize losses due to threats and weaknesses (withdrawal strategy).

Based onobtainedcoefficients of variation, the strengths of the knowledge-based companies are more than their weaknesses. On the other hand,the threats are stronger than opportunities, so the strategic deployment flexibility had been in ST area and dominant strategy is defined as diversification strategy .It should be noted that determining the area of strategic deployment flexibility has not always been defined based on the same weighting coefficient of SWOT itemsand it is possible to be the main assumption in regard to item weighting, in this study, the number of items in each component are considered identical and the same weight for each component has been taken into account.

Table 5. Coefficient of variation, mean and standard deviation of the components of SWOT analysis

\begin{tabular}{llll}
\hline SWOT & Mean & Standard deviation & Coefficient of variation \\
\hline weaknesses & 5.6 & 2.79 & 0.500 \\
strengths & 7.39 & 2.28 & 0.310 \\
threats & 6.93 & 2.51 & 0.365 \\
opportunities & 4.98 & 2.35 & 0.553 \\
\hline
\end{tabular}




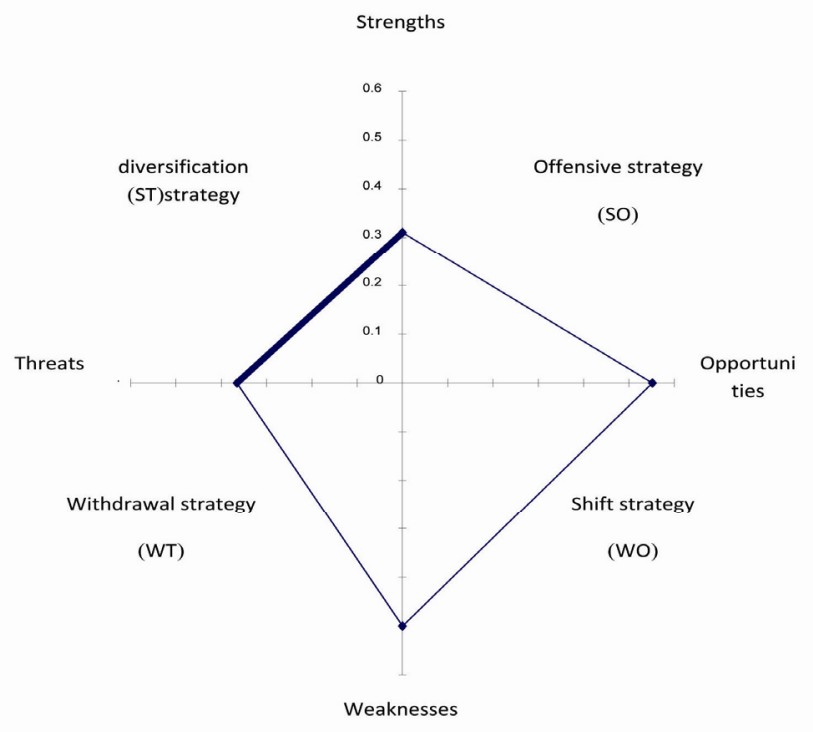

Figure 1. The strategic deployment flexibility area of knowledge-based companies

Schematic diagram of the strategic deployment flexibility area can be drawn as figure 1. It should be mentioned that the quadrilateral method was used to delineate areas of thestrategic deployment flexibility. In this method, coefficient amount of variation of each of the four components are marked on the graph and the four points are connected to each other and as a result a quadrilateral is obtained.The obtained quadrilateral is closer to coordination origin if it has less tendency toward an area or as much as it has this tendency or it is more desirable if thearea of this part of quadrilateral is less in desired area

And that area will be dominant area compared to other areas. According to inappropriate conditions ofthe external environment of the knowledge-based companies and possibly the undesirable sales situation of company's products and low growth of product market, it is better for the companies to approach to diversification strategies, especially in heterogeneous variation.

It is well known that the organization must pull out its sources from present activity fields and tries to work in another field if there are competitive advantages for which knowledge-based companies are eligible and if there is negative attention in the market. If these strategiesare associated with high costs or for any other reason they are not possible, knowledge-based companies can apply concentration strategies and priorities for market and product development in order to offer its products in new markets in this way or offer its present products to the current markets with improving them. Generally speaking, it can be said that knowledge-based companies should try to maintain their distinctive competencies and preferably do not expose themselves to large risks.

\section{Conclusion and Recommendations}

For many managers of Iranian knowledge-based companies the dependency on selling a product is an ongoing concern. These firms have witnessed rapid growth in the early periods usually with offering a successful product and then over the time, they have witnessed the reduction of sales growth and stability or even declining sales.Such reductions can have several reasons such as the emergence of new competitors, market saturation, or entering alternative products or reducing demand due to the recession. Diversity is of firstideas that are usually among the first to respond to this situation. Althoughwhat often motivate to create diversity in business is the tendency to growth and development, however, it is seen that companies also seek diversity in a period of recession or crisis. Three main levels of diversification can be provided for knowledge-based companies:

1- Diversity resulted from closely related products: In the case of various knowledge-based companies it is possible to have different products and services but they can have a type of similarity such as same customers, same suppliers or same overhead costs. But very company has same customers, same distribution stations (supermarkets), various common suppliers and competitors. As a result, these companies can take advantage of the benefits of working together on common fields;

2- Diversity based on the main merit: In the case, different knowledge-based companies have quite diverse 
products and services. However, these companies are able to possess a common main merit, which is used in various sectors;

3- Diversity of unrelated products: In some cases, various knowledge-based companies have little similarities in terms of products, services and technology. However, they benefit from certain resources such as financial sources and management skills that the parent company will give them.

With regard to the issues raised, following recommendation can be provided:

- Adding new and unrelated products that can increase revenues significantly from selling current products and services;

- Knowledge-based companies should use the current distribution channels and supply new products to existing customers;

- When the knowledge-based company has earned the chance and can work on unrelated field,it will purchase a firm.From company's point of view, this situation is a good opportunity to invest;

- Knowledge-based companies should take advantage of their ability to create new products. To this end, in collaboration with other similarcompanies can increase profits for the company:

- In addition to the diversity of products and services, these companies should create necessary diversity in their progress programs.

\section{References}

Albino, V., Garavelli, A. C., \& Gorgogline, M. (2004). Organization and technology in knowledge transfer. Benchmarking An International Journal, 11(6). 12-13. http://dx.doi.org/10.1108/14635770410566492

Albrecht, K. (2010). The power of minds at work: organizational intelligence in action. American Management Association.

Allahyarifard, N., \& Abbasi, R. (2011). The review of suitable pattern of organizational structure of knowledge-based companies. Professional Journal of Parks and Incubators.

Bagheri, S. K. (2003). Measuring $R \& D$ or innovation, the need for innovation evaluation and covering the activities of design and engineering in Iran. 2nd Congress on research methods in science and engineering, Imam Hossein University.

Bandarian, R. (2009). Marketing and commercialization of new technologies, processes, and facilitating andcritical factors of success. Journal of Technology, 19, 39.

Behboudi, D., \& Amiri., B. (2010). Long term relationship of knowledge-based economy and economic growth in Iran. Journal of Politics, Science and Technology.

Berg, D. (2005). Technology management: brand value and the technology sector. 14th International Conference on Management of Technology, 22-25 May 2005, Vienna, Austria.

Fakour, B., \& Ansari, M. T. (2010). Evaluationof methods and technology gain resources in small selected firms of Iran. Journal of Science and Technology Policy, 4, 105-93.

Farjadi, G., \& Riahi, P. (2007). Study of local market for Iranian science and technology parks. Quarterly Journal of Research and Planning in Higher Education, 13(2), 20-48.

Goudarzi. (2011). The pattern of technology commercialization Process in governmental research institutes. Scientific and research Journal of Science and Technology Policy, 4(2), 41-56.

Hosseini, J., \& Araste, H. (2013). External factors affecting research results commercialization. Journal of Research and Planning in Higher Education, 67, 45-68.

Malekzadeh, G. H. (2007). Technology marketing, and the commercialization of research results. Quarterly Journal of Technologydevelopment.

McGann, J. (2007). Survey of Thins Tanks, a Summary Report. Foreign Policy Research Institute, USA.

Moghimi, M. (2010). The impact of environmental factors on ideas and research results commercialization. Strategic Management Studies, 2, 113-126.

Mohammadi, F. (2009). Technology development and research finding commercialization, barriers and solutions. Iran Polymer Engineering and Science Society, 1-3.

Moreau, F. (2006). Strategy Development Process in Bernasconi, Michel; Harris, Simon; Moensted, Mette, 
High-tech Entrepreneurship; Managing innovation, variety and uncertainity. Routldge.

Mousaii, A. (2008). Designing a model in order to determine opportunities and their commercialization in develop and research centers. Professional journal of parks and incubators, 14, 13-21.

Mudambi, S., Oliva, T. A., \& Thomas, E. F. (2009). Industrial marketing firms and knowledge transfer: Toward a basic typology of community structures. Industrial Marketing Management, 38(2), 181-190. http://dx.doi.org/10.1016/j.indmarman.2008.12.006

Pourezzat, A. A. (2010). Explanation of barriers to entrepreneurship and the commercialization of knowledge in Tehran University. Journal of Science and Technology Policy.

Pourezzat, A. A., \& Heydari, E. (2011). Identification and grouping challenges and barriersof knowledge commercialization using Q method. Scientific and technological Journal of Policy Research, 4, 49-62.

Radfar, R., Khamse, A. M., \& Hessam. (2009). Technology commercialization, an effective factor in development of technology and economy. Professional Journal of Parks and Incubators, 20, 33-40.

SarmadSaeidi, S., \& Mamaghani, A. (2011). New product development and product development productivity using marketing approach. Management Journal, 22, 25-26.

Zhang, J. (2003). High-Tech Start-Ups and Industry Dynamics in Silicon Valley. Public Policy Institute of California. Retrieved from http://www.ppic.org/content/pubs/report/R_703JZR.pdf

\section{Copyrights}

Copyright for this article is retained by the author(s), with first publication rights granted to the journal.

This is an open-access article distributed under the terms and conditions of the Creative Commons Attribution license (http://creativecommons.org/licenses/by/3.0/). 